\title{
Commentary: Substandard medicines are the priority for neglected tropical diseases
}

\author{
Thomas P C Dorlo senior scientist ${ }^{12}$, Raffaella M Ravinetto senior scientist ${ }^{3}$, Jos H Beijnen \\ professor $^{12}$, Marleen Boelaert professor ${ }^{4}$
}

${ }^{1}$ Department of Pharmacy and Pharmacology, Slotervaart Hospital, The Netherlands Cancer Institute, Amsterdam, Netherlands; ${ }^{2}$ Division of Pharmacoepidemiology and Clinical Pharmacology, Utrecht Institute for Pharmaceutical Sciences, Utrecht University, Utrecht, Netherlands; ${ }^{3}$ Department of Clinical Sciences, Institute of Tropical Medicine, Antwerp, Belgium; ${ }^{4}$ Department of Public Health, Institute of Tropical Medicine, Antwerp, Belgium

\begin{abstract}
Attaran and colleagues propose new definitions for the quality of medicines and plead for a global treaty tackling both substandard production and falsification. ${ }^{1}$ We support this, as the international community tends to concentrate its efforts on falsified medicines, whereas substandard drugs are just as much a threat. ${ }^{2}$ Moreover, in practice the distinction can be difficult.

We recently described the case of a poor quality medicine from Bangladesh that did not contain its active ingredient, miltefosine. ${ }^{34}$ The medicine, authorised by the national regulatory authorities, was manufactured locally for the Bangladeshi elimination programme for visceral leishmaniasis, a neglected tropical disease. The problem surfaced only after reports of abnormally high numbers of treatment failure.
\end{abstract}

According to the proposed definitions, this medicine is substandard. Whether it is falsified remains unclear. Attaran et al argue that a criminal intent would make the manufacturing worth a more serious punishment. We disagree with this approach, not only because it is often impossible to discern a manufacturer's intent but also because the effect of poor quality medicines on public and individual health should be the prime concern. The substandard miltefosine may have been the result of a lack of resources, negligence, or fraud, but the outcome is the same: unnecessary and preventable morbidity and mortality. In resource poor countries, substandard medicines are predictably the result of structural negligence or poor manufacturing practices. ${ }^{5}$ Structural negligence in pharmaceutical production should never be considered less important than a deliberate or fraudulent action because the consequences are equally serious for the final user.

\section{Prioritising prevention}

Although a global treaty will provide a welcome legal framework, we want to see problems with medicine quality anticipated rather than dealt with afterwards. The lack of resources of many regulatory authorities prevents them from enforcing standards on manufacturers and distributors. The
World Health Organisation should help strengthen regulation in resource limited countries. In the public sector appropriate tender procedures should be developed, with adequate quality criteria for manufacturers and products, and well defined procurement policies. ${ }^{6}$ These procedures should be public, to maximise transparency and accountability towards citizens.

\section{Disproportionally affecting neglected tropical diseases}

Traditionally, medicine quality has been ignored in neglected tropical diseases, though scattered reports show that serious problems exist. For visceral leishmaniasis at least three other incidents with poor quality medicines have been described, from India, Nepal, and Sudan. ${ }^{7-9}$ All came to light only because of abnormally high failure rates or life threatening toxicities, though the poor manufacturing practices could have been detected in advance by regulatory inspections. Attaran and colleagues point out that falsification is opportunistic and often occurs with cheap generics. Likewise, the lack of financial incentives in the market for medicines for neglected tropical diseases does not protect these medicines from illegitimacy. Public sector tenders predictably result in purchases from the cheapest possible supplier, with no regard for quality specifications. Patients with these neglected diseases may therefore be disproportionally at risk from substandard medicines.

Internationally, guidance should be provided for the quality assurance of medicines for neglected tropical diseases. The WHO prequalification programme provides such guidance based on structural preventive measures, but it is currently limited to HIV/AIDS, malaria, tuberculosis, and reproductive health. This year, an important first step was made when the programme invited manufacturers to submit two antihelminthic drugs for evaluation, but expansion is needed. Quality assurance is further complicated by a lack of monographs for medicines for 
neglected diseases in the major international pharmacopoeias, though the United States Pharmacopeia has recently opened an online section to make quality standards for medicines approved in any country publicly available (www.usp-mc.org/).

The focus of concerted actions should be on the effect of poor quality medicines as a whole and should tackle structural substandard production. A patient centred, integrated approach to protecting neglected patients from all dangerous medicines cannot be further postponed.

Competing interests: All authors have completed the ICMJE unified disclosure form at www.icmje.org/coi_disclosure.pdf (available on request from the corresponding author) and declare: no support from any organisation for the submitted work; no financial relationships with any organisations that might have an interest in the submitted work in the past three years; no other relationships or activities that could appear to have influenced the submitted work.

Provenance and peer review: Not commissioned; not externally peer reviewed.
1 Attaran A, Barry D, Bashir S, Bate R, Benton D, Chauvin J, et al. How to achieve international action on falsified and substandard medicines. BMJ 2012;345:e7381.

Katsnelson A. Substandard drugs overshadowed by focus on fakes. Nat Med 2010;16:364.

3 Dorlo TPC, Eggelte TA, Schoone GJ, De Vries PJ, Beijnen JH. A poor-quality drug for the treatment of visceral leishmaniasis: a case report and appeal. PLoS Negl Trop Dis 2012;6:e1544.

4 Dorlo TPC, Eggelte TA, de Vries PJ, Beijnen JH. Characterization and identification of suspected counterfeit miltefosine capsules. Analyst 2012;137:1265-74.

5 Caudron J-M, Ford N, Henkens M, Macé C, Kiddle-Monroe R, Pinel J. Substandard medicines in resource-poor settings: a problem that can no longer be ignored. Trop Med Int Health 2008;13:1062-72.

6 Ravinetto RM, Boelaert M, Jacobs J, Pouget C, Luyckx C. Poor-quality medical products: time to address substandards, not only counterfeits. Trop Med Int Health 2012;17:1412-6.

7 Rijal S, Chappuis F, Singh R, Boelaert M, Loutan L, Koirala S. Sodium stibogluconate cardiotoxicity and safety of generics. Trans R Soc Trop Med Hyg 2003;97:597-8.

8 Sundar S, Sinha PR, Agrawal NK, Srivastava R, Rainey PM, Berman JD, et al. A cluster of cases of severe cardiotoxicity among kala-azar patients treated with a high-osmolarity lot of sodium antimony gluconate. Am J Trop Med Hyg 1998;59:139-43.

9 Boelaert M, Le Ray D, Van Der Stuyft P. How better drugs could change kala-azar control. Lessons from a cost-effectiveness analysis. Trop Med Int Health 2002;7:955-9.

Cite this as: BMJ 2012;345:e7518

(c) BMJ Publishing Group Ltd 2012 